\title{
De relatie tussen transactie- en produktiekosten
}

\author{
Mr. J. van der Bij
}

\section{Inleiding}

De laatste jaren is de overtuiging gegroeid dat kennis omtrent het verloop van de produktiekosten onvoldoende aanknopingspunten biedt voor een economische verklaring van organisatievormen. Een bevredigende verklaring voor de grote diversiteit aan organisatievormen zou wel binnen het bereik van de economische wetenschap liggen, indien een andere categorie van kosten in de beschouwingen betrokken wordt. Naast de produktiekosten zou men tevens rekening moeten houden met de transactiekosten.

De belangstelling voor transactiekosten mag dan relatief nieuw zijn, het begrip als zodanig is dat zeker niet. Reeds in 1937 voerde Coase de transactiekosten op als de verklarende factor voor het bestaan van hiërarchisch georganiseerde ondernemingen (Coase, 1937). Coase stelde dat indien de kosten van markttransacties gelijk zijn aan nul, er geen behoefte zou bestaan aan organisaties die deze markttransacties vervangen door intern verrichte produktiehandelingen. Waarom zou een onderneming ook maar één persoon in dienst nemen, wanneer via de markt iemand zonder extra kosten voor enkele uren ingehuurd kan worden? Of waarom zou een consument überhaupt een onderneming inschakelen, wanneer hij alle benodigde produktiefactoren zonder toegevoegde kosten kan verwerven en combineren? Later heeft Coase de inhoud van het transactiekostenbegrip nader proberen te bepalen (Coase, 1960). Transactiekosten zijn naar zijn mening alle kosten die optreden tijdens het zoeken naar een geschikte contractpartner, het voeren van contractonderhandelingen, het opstellen van een contract en het toezien op een correcte uitvoering van het contract door de wederpartij.

Ruwweg kan men stellen dat in de traditionele opvatting de omvang van de produktiekosten afhangt van de schaarse middelen die opgeofferd worden tijdens de vervaardiging van het goed, terwijl de omvang van de transactiekosten afhangt van de schaarse middelen die opgeofferd worden in het kader van de ruil van het reeds vervaardigde goed. De gedachte is vervolgens dat zowel de produktie als de ruil in een institutioneel kader geplaatst moeten worden, dat uitzicht biedt op minimalisering van de som van de produktieen transactiekosten.

Er hangen echter nog al wat problemen samen met de notie dat de som van deze twee categorieën van kosten geminimaliseerd moet worden. In de eerste plaats is de inhoud van het transactiekostenbegrip onvoldoende bepaald. Wanneer alle kosten die verband houden met de totstandkoming en uitvoering van contracten tot transactiekosten bestempeld worden, is het onderscheid met produktiekosten die optreden binnen de organisatie onvoldoende duidelijk. Ook binnen de organisatie komen immers tal van contractuele en quasi-contractuele verhoudingen voor, zoals bijvoorbeeld arbeidsovereenkomsten en interne leveringsovereenkomsten. De volgende logische stap is ook de transactiekosten die optreden binnen de organisatie in de afweging te betrekken, waardoor het gevaar van dubbeltelling met produktiekosten dreigt. ${ }^{\prime}$ In de tweede plaats kan een onvoldoende bepaald transactiekostenbegrip gebruikt worden, om elke in de weelderige praktijk aangetroffen organisatievorm te karakteriseren als het resultaat van een geslaagde poging potentiële transactiekosten te reduceren. Een dergelijk inhoudsloos begrip verklaart alles en tegelijkertijd niets.

Mr. J. van der Bij studeerde fiscaal recht aan de Rijksuniversiteit Leiden en is momenteel werkzaam bij de vakgroep staats- en bestuursrecht van de juridische faculteit van de Vrije Universiteit te Amsterdam. 


\section{MAB}

\section{Het transactiekostenbegrip van Williamson}

Williamson heeft getracht een eigen en beter omlijnde inhoud te geven aan het transactiekostenbegrip (Williamson, 1985). Allereerst geeft hij een omschrijving van de omstandigheden waaronder het contract tot stand komt en uitgevoerd wordt. Zo realiseren de partijen zich dat zij in het contract voorziening treffen voor een nog onbekende toekomst. Het is dus onmogelijk voor iedere eventualiteit reeds een oplossing op te nemen in het contract. Dit klemt des te meer aangezien een contractpartij zich zal realiseren dat de wederpartij in beginsel geneigd is tot het vertonen van opportunistisch gedrag. In een wereld waarin slechts een beperkte kennis omtrent de toekomst bestaat maar waarin geen opportunisme voorkomt, zouden overeenkomsten maar één standaardbepaling hoeven te bevatten voor onvoorziene omstandigheden. Deze bepaling zou stipuleren dat voor elke onvoorziene situatie een oplossing gevonden moet worden, waarvan alle contractpartijen gelijkelijk profiteren of nadeel ondervinden. In een wereld waarin echter sprake is van zowel beperkte cognitieve vermogens als opportunistisch gedrag, zijn ook aan het toezicht houden op de verrichtingen van de wederpartij substantiële kosten verbonden.

Tevens onderscheidt Williamson de factoren die bepalen welk institutioneel kader gekozen zal worden door partijen. Het betreft hier de frequentie van de transacties, de onzekerheid waarmee de uitvoering van het contract omgeven is en tenslotte het specifieke karakter van de vereiste investeringen (Van der Bij, 1991). Deze drie factoren bepalen de mate van afhankelijkheid die tussen partijen bestaat. Wanneer partijen talrijke transacties verrichten en de onzekerheid groot is, zal de wederzijdse afhankelijkheid eveneens groot zijn. De talrijke transacties hebben tot gevolg dat zij veel met elkaar te maken hebben, en de onzekerheid dat zij op elkaar aangewezen zijn voor het vinden van een tevredenstellende oplossing voor onverwachte problemen.

Het specifieke karakter van de vereiste investeringen verdient nadere uitleg. Wanneer de producent een investering pleegt die specifiek is voor een transactie, heeft dit tot gevolg dat het rende- ment van de investering aanzienlijk geringer is wanneer het contract met de huidige partij geen vervolg krijgt. Andersom kan ook de afnemer afhankelijk worden, omdat andere producenten niet over de bijzondere faciliteiten en kennis beschikken die de huidige contractpartij inmiddels in huis heeft. Hierbij kan bijvoorbeeld gedacht worden aan speciaal voor de afnemer geschreven software, waarbij het software-house tevens voor de training van het personeel van de afnemer zorg draagt. De initiële investeringen van het software-house zijn vooral lonend wanneer door middel van vervolgopdrachten het systeem uitgebouwd en up to date gehouden kan worden. Voor de afnemer geldt dat hij niet zomaar naar een ander software-house kan stappen dat over dezelfde kennis van dit specifieke systeem beschikt.

Uitgaande van de mate van wederzijdse afhankelijkheid zullen partijen voor een bepaald juridischinstitutioneel kader kiezen. Is de afhankelijkheid zeer gering dan gaat de voorkeur uit naar een klassiek contract. Het gaat hier vooral om homogene standaardprodukten, die binnen een kort tijdsbestek overgedragen kunnen worden. Mochten de investeringen tenminste ten dele specifiek zijn en de transacties een incidenteel karakter hebben, dan ligt een neo-klassiek contract voor de hand. Hierbij moet men vooral denken aan technisch complexe goederen, waarbij een betrekkelijk lange periode verstrijkt tussen het moment van het sluiten van de overeenkomst en de levering. Een huis dat met inachtneming van de wensen van de opdrachtgever gebouwd wordt, kan als voorbeeld gelden. Het kenmerkende van het institutionele kader is het beroep dat door partijen op technische deskundigen gedaan kan worden, wanneer problemen rijzen in het kader van de uitvoering van de overeenkomst. Een neo-klassiek contract zal dan ook vaak voorzien in de mogelijkheid problemen voor te leggen aan een arbitragecommissie. Een uitgebreider en daardoor kostbaarder institutioneel kader loont niet de moeite, gezien het incidentele karakter van de transacties.

Als laatste zijn er nog de goederen en diensten die frequent tussen dezelfde partijen verhandeld worden en specifieke investeringen vereisen. Hier 


\section{MAB}

kan de wederzijdse afhankelijkheid zo groot zijn, dat het de moeite loont de mogelijkheid van opportunistisch gedrag door een onafhankelijke contractpartner uit te sluiten en over te gaan tot internalisering van de transactie. De organisatie verricht de handeling dan zelf en maakt geen gebruik van de markt als intermediair.

\section{Transactiekosten en het principaal-agent probleem}

Het grote voordeel van de benadering van Williamson is dat hij de nadruk legt op de essentiële elementen in een contractuele relatie. Onzekerheid alsmede de mogelijkheid van opportunistisch gedrag door de wederpartij zijn wezenlijk voor de contractuele relatie en de hieraan verbonden nadelen worden groter naarmate de wederzijdse afhankelijkheid toeneemt. In feite openbaart zich in de contractuele relatie een klassiek principaal-agent probleem. De voorwaarden waaronder de overeenkomst tot stand komt en uitgevoerd wordt, kenmerken zich door de aanwezigheid van informatie asymmetrie. De agent is volledig geïnformeerd over zijn eigen intenties en feitelijk handelen, terwijl de principaal niet over dezelfde informatie kan beschikken. Dit stelt de agent in staat om binnen een zekere marge zijn eigen belangen te behartigen, ten koste van de principaal. Deze vrijheid ontstaat doordat de agent over technische of andersoortige kennis beschikt waarop de principaal niet kan bogen zodat de agent een informatievoorsprong verwerft, of doordat de principaal bepaalde handelingen van de agent eenvoudigweg niet kan waarnemen. De werkelijke kosten die samenhangen met een transactie vloeien dan ook voort uit het principaal-agent probleem.

Het grote probleem is en blijft de afbakening van het transactiekostenbegrip. Zo gaf Cheung in 1989 nog de volgende definitie van het transactiekostenbegrip: '....any arrangement that requires the use of a manager, a director, a supervisor, a clerk, an enforcer, a lawyer, a judge, an agent, or even a middleman implies the presence of an organization. These professions would not exist in the Crusoe economy, and payments for their employment are transaction costs' (Cheung,
1989). Het zal duidelijk zijn dat een dergelijke omschrijving zeer ruim, arbitrair en weinig bepaald is. Het zou naar mijn mening de voorkeur verdienen bij de omschrijving van de transactiekosten niet uit te gaan van de feitelijke uitgaven, die verricht worden in het kader van de voorbereiding en uitvoering van de overeenkomst.

De transactiekosten bestaan echter uit het verschil tussen enerzijds het ideale resultaat van een optimale contractuele relatie waarbij de principaal en de agent identieke belangen behartigen en anderzijds het resultaat van een sub-optimale contractuele relatie waarbij principaal en agent ten dele tegengestelde belangen najagen. De transactiekosten bereiken een maximale omvang, indien de principaal geen enkele poging onderneemt het zelfzuchtige gedrag van de agent te beteugelen. Uit deze vorm van 'verspilling' vloeien voor de principaal reële kosten voort, die zich ook laten kwantificeren. De kosten die voortvloeien uit het principaal-agent probleem kunnen bijvoorbeeld bestaan uit een inferieure prestatie of een te hoge prijs.

De schaarse middelen die opgeofferd worden in het kader van de opbouw en instandhouding van een organisatie waarbinnen overeenkomsten gesloten alsmede uitgevoerd worden, behoren deel uit te maken van de produktiekosten in ruime zin. Deze investeringen in de organisatie komen zeker niet overeen met de transactiekosten zoals Cheung en anderen stellen, maar geven hoogstens een indicatie voor de ruimte die een agent nog heeft voor het toeëigenen van boven-contractuele voordelen.

Naar mijn mening zou het op dit punt aanbeveling verdienen te streven naar integratie van de transactiekostentheorie en de principaal-agenttheorie. Tot nu toe is de principaal-agenttheorie vooral toegepast bii de analyse van hiërarchische verhoudingen, maar eigenlijk bestaat er geen reden deze beperking te handhaven. In navolging van Eggertsson kan de principaal-agenttheorie aangemerkt worden als een tak van de transactiekostentheorie. Eggertsson verwoordde het als volgt. 'The theory of agency is a branch of the economics of transaction costs. Although the theory is most commonly used to analyze hierarchial relationships, it has a general application to all forms 


\section{MAB}

of exchange. An agency relationship is established when a principle delegates some rights for example, user rights over a resource - to an agent who is bound by a (formal or informal) contract to represent the principal's interests in return for payment of some kind' (Eggertsson, 1990). Bij de kwantificering van de transactie- en de produktiekosten is het belangrijk om in het oog te houden, dat beide categorieën van kosten afhankelijk zijn van de technische produktiefunctie. De transactiekosten kunnen namelijk alleen door de principaal beteugeld worden, indien deze voldoende inzicht heeft in de produktiefunctie van de agent. De mate waarin de principaal inzicht moet hebben in de produktiefunctie van de agent, is afhankelijk van de kenmerken van het betreffende goed. De noodzaak voor de principaal inzicht te hebben in de produktiefunctie van de agent is zeer gering, wanneer de produktieve inspanningen van de agent belichaamd zijn in een homogeen standaardprodukt dat binnen een kort tijdsbestek overgedragen kan worden. Het volstaat wanneer de afnemer in staat is de eigenschappen van het produkt te beoordelen. Het traditionele Walrasiaanse model wordt het dichtst benaderd daar waar de formulering en effectuering van eigendomsrechten optimaal is door de technische karakteristieken van het homogene goed. Dit is niet verwonderlijk aangezien onder deze omstandigheden de transactiekosten buitengewoon laag zijn en het prijsmechanisme optimaal kan functioneren, zodat het model van de neoklassieke economen uitstekend voldoet.

Inzicht van de afnemer in de produktiefunctie van de wederpartij is daarentegen wel belangrijk indien een aanzienlijke periode verstrijkt tussen het sluiten van de obligatoire overeenkomst en de levering van het goed. Een dergelijk tijdsverloop treedt veelvuldig op wanneer de agent bij de vervaardiging van het goed rekening houdt met de wensen van de principaal, zodat de betrokkenheid van de principaal bij het produktieproces reeds daarom groter is dan in het geval van een standaardprodukt. Het ligt voor de hand dat de principaal kostbare alternatieve voorzieningen moet treffen in het geval de agent het goed niet op het verwachte tijdstip kan leveren.

De noodzaak inzicht te hebben in de produktie- functie is echter het grootst wanneer de prestaties van de agent bestaan uit een continue stroom van diensten. Vooral wanneer slechts de inspanningen van de agent bepalend zijn voor de beantwoording van de vraag of deze de op hem rustende verbintenis nagekomen is, zal de principaal zich een nauwkeurig inzicht moeten verschaffen in het doen en laten van de agent. Bij contractuele verplichtingen die gekwalificeerd kunnen worden als inspanningsverbintenissen, is de noodzaak voor de principaal om inzicht te hebben in het produktieproces het grootst.

Voorts kan bij de definitie van het transactiekostenbegrip het onderscheid tussen vervaardiging en ruil overboord gezet worden, indien het principaal-agent probleem als zodanig centraal staat. Wanneer door de principaal de mogelijkheden voor de agent tot het toeëigenen van boven-contractuele voordelen beperkt worden, zal dit de opoffering van schaarse middelen en een verhoging van de kostprijs tot gevolg hebben. De agent kan zowel deel uitmaken van de organisatie als een meer onafhankelijke positie innemen. Een verlaging van de transactiekosten gaat dus altijd gepaard met een gelijktijdige verhoging van de produktiekosten. Het komt uiteindelijk aan op het bepalen van de omvang van het organisatieniveau waarop een verhoging van de produktiekosten, niet langer resulteert in een meer dan evenredige verlaging van de transactiekosten. Het organisatieniveau wordt bepaald door de mate van toezicht op de agent. In een bureaucratische organisatie is het organisatieniveau bijvoorbeeld zeer hoog, omdat de agenten binnen de organisatie geacht en gedwongen worden de voorschriften van de principalen precies te volgen. Door het ver doorgevoerde toezicht zijn de transactiekosten relatief laag, maar de overheadkosten daarentegen zeer hoog. Wanneer gebruik gemaakt wordt van de diensten van een volstrekt onafhankelijke agent, doet zich een omgekeerde situatie voor.

Overigens zal de principaal zich bewust moeten zijn van het feit dat een minimum aan transactiekosten zal optreden, ongeacht de complexiteit van het institutionele kader. Ook bij volledige internalisering zal de mogelijkheid van 'shirking' (Alchian en Demsetz, 1972) en het najagen van 


\section{MAB}

eigen doelstellingen door werknemers niet geheel uitgesloten kunnen worden. Jensen en Meckling gaan er bijvoorbeeld van uit dat naast de kosten die voortvloeien uit het toezicht houden op de agent er voor de principaal nog een 'risidual loss' optreedt. Jensen en Meckling stellen het volgende. 'However, it is generally impossible for the principal or the agent at zero cost to ensure that the agent will make optimal decisions from the principal's viewpoint. In most agency relationships the principal and the agent will incur positive monitoring and bonding costs (non-pecuniary as well as pecuniary), and in addition there will be some divergence between the agent's decisions and those which would maximize the welfare of the principal. The dollar equivalent of the reduction in welfare experienced by the principal due to this divergence is also a cost of the agency relationship, and we refer to this latter cost as the 'residual' loss' (Jensen en Meckling, 1976).

De additionele investeringen in het institutionele kader kunnen dus op een bepaald punt resulteren in extra produktiekosten, die niet gecompenseerd worden door een verdere reductie van de transactiekosten. Er is dus een harde kern van transactiekosten oftewel het transactiekostenrestant, dat niet voor verdere minimalisatie in aanmerking komt. De inspanningen van de principaal moeten dan ook gericht worden op een reductie van de totale transactiekosten minus het transactiekosten-restant. Het verschil tussen deze beide grootheden is het transactiekosten-écart en dit deel van de transactiekosten dient geminimaliseerd te worden.

\section{Een voorbeeld van minimalisering van het transactiekosten-écart}

Ik zal om het vorenstaande te illustreren een eenvoudig modelmatig voorbeeld geven. De bedoeling is de bepaling van het organisatieniveau waarbij het transactiekosten-écart geminimaliseerd wordt, tegen de laagste totale kosten. Stel dat de maximale transactiekosten in afwezigheid van enige controle op de agent $f$ 1500,bedraagt. De principaal vindt een niveau van $f$ 250,- aanvaardbaar, aangezien extra inspanningen alleen extra kosten veroorzaken en niet resulteren in een verdere reductie van de transactiekosten. Het te minimaliseren transactiekostenécart bedraagt dus (1500-250) $f$ 1250,- Een daling van het transactiekosten-écart kan slechts bewerkstelligd worden door een toename van het organisatieniveau oftewel een investering in de creatie en instandhouding van het institutionele kader waarbinnen de transactie zich voltrekt. Deze kosten maken deel uit van de kostprijs en behoren dus tot de produktiekosten. Dit alles bij een constant produktievolume, waarbij alleen het organisatieniveau varieert. Het gaat hier dus niet om de bepaling van het optimale produktievolume. Het voorbeeld ziet er als volgt uit:

$$
\begin{array}{ll}
\mathrm{PK}= & 100 \mathrm{ON}+100 \\
\mathrm{TCK}= & \mathrm{TCKE}+\mathrm{TCKR} \\
\mathrm{TCKE}= & -2 \frac{1}{2} \mathrm{PK}+1500 \\
& 0 \leq \mathrm{TCKE}
\end{array}
$$

$\mathrm{TCKR}=250$

INTK $=\mathrm{PK}+\mathrm{TCKE}+\mathrm{TCKR}$

Waarbij:

$\mathrm{PK}=$ Produktiekosten

$\mathrm{ON}=$ Organisatieniveau .

TCK $=$ Transactiekosten.

TCKE $=$ Transactiekosten-écart.

TCKR $=$ Transactiekosten-restant.

INTK = Integrale kosten.

Dit levert in tabelvorm de volgende gegevens op.

\begin{tabular}{rrrrr}
\hline ON & PK & TCKE & TCKR & INTK \\
\hline 1 & 200 & 1000 & 250 & 1450 \\
2 & 300 & 750 & 250 & 1300 \\
3 & 400 & 500 & 250 & 1150 \\
4 & 500 & 250 & 250 & 1000 \\
5 & 600 & 0 & 250 & 850 \\
6 & 700 & 0 & 250 & 950 \\
7 & 800 & 0 & 250 & 1050 \\
8 & 900 & 0 & 250 & 1150 \\
9 & 1000 & 0 & 250 & 1250 \\
10 & 1100 & 0 & 250 & 1350 \\
\hline
\end{tabular}

Het optimale organisatieniveau wordt bereikt op het punt waarop het transactiekosten-écart geminimaliseerd is en de integrale kosten het 


\section{MAB}

laagste punt hebben bereikt, dat wil zeggen bij organisatieniveau 5.

\section{Conclusie}

Voor de bepaling van de optimale omvang van de organisatie is het onvoldoende uitsluitend inzicht te hebben in het verloop van de produktiekosten, maar moet tevens aandacht geschonken worden aan het verloop van de transactiekosten. Het door Coase gehanteerde transactiekostenbegrip leidt tot dubbeltelling met de produktiekosten en is inhoudelijk onvoldoende bepaald. Het voordeel van de benadering van Williamson is gelegen in de omstandigheid dat hij de twee essentiële elementen in de contractuele relatie centraal stelt, namelijk onzekerheid en opportunisme. Een beschrijving van de contractuele relatie in deze termen geeft aan dat we te maken hebben met een klassiek principaal-agent probleem. De transactiekosten bestaan dan ook uit het verschil tussen enerzijds het ideale resultaat van een optimale contractuele relatie waarbij de principaal en de agent identieke belangen behartigen en anderzijds het resultaat van een sub-optimale contractuele relatie waarbij principaal en agent ten dele tegengestelde belangen najagen. Voor een deel van de transactiekosten geldt dat een verdere reductie niet meer mogelijk is, aangezien een constant minimum aan opportunistisch gedrag binnen ieder juridisch-institutioneel kader voor zal komen. Bij de bepaling van het optimale organisatieniveau moet daarentegen gestreefd worden naar een minimalisatie van het transactie- kosten-ècart. Op deze wijze kunnen belangrijke indicaties gevonden worden voor de bepaling van het optimale organisatieniveau.

\section{Literatuur}

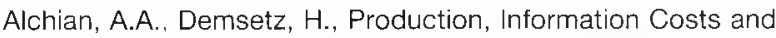
Economic Organization, American Economic Review, vol. 62, 1972 , p. 786.

Bij, van der, J., De uitbesteding van de produktie van collectieve goederen, Financieel Overheidsmanagement, jrg. 4, nummer 4, april 1991.

Cheung, S.N.S., Economic Organization and Transaction Costs, opgenomen in: The New Palgrave, Allocation, Information and Markets, London/Basingstoke, The Macmillan Press Limited. 1989, pp. 77-78.

Coase, R.H., The Nature of the Firm, Economica, Vol 4., 1937, p. 392.

Coase, R.H.. The Problem of Social Cost, Journal of Law \& Economics, Vol. 3, 1960, p. 15.

Eggertsson, T., Economic behavior and institutions, Cambridge/ New-York, Cambridge university press, 1990, p. 40.

Jensen, M.C., Meckling, W.H., Theory of the Firm: Manageriat Behavior, Agency Costs and Ownership Structure, Journal of Financial Economics 3 (1976), North Holland Publishing Company, p. 308.

Klein, B., Contracting Costs and Residual Claims: The Separation of Ownership and Control, Journal of law \& Economics, vol. 16. June 1983.

Williamson, O.E., The Economic Institutions of Capitalism; Firms, Markets, Relational Contracting. New York, The Free press, 1985.

\section{Noot}

1 Klein merkt dan ook op dat Coase ten onrechte geen rekening houdt met de transactiekosten die binnen de onderneming optreden. 